\title{
DERIVATION OF VOELLMY'S MAXIMUM SPEED AND RUN-OUT ESTIMATES FROM A CENTRE-OF-MASS MODEL
}

\author{
By D. M. MCCLUNG \\ (British Columbia Regional Station, Division of Building Research, National Research Council \\ of Canada, 3904 West Fourth Avenue, Vancouver, British Columbia V6R 1P5, Canada)
}

\begin{abstract}
The commonly used maximum speed and run-out equations for flowing avalanches given by Voellmy's (1955) method are considered from a more general model proposed by Perla and others. (1980). Equations analogous to those of Voellmy are derived and the approximations are defined from the point of view of the more general model.

RÉSUMÉ. La vitesse maximum de Voellmy el estimations des courses d'avalanches à partir d'un modèle à masse concentrée. Les équations d'usage courant pour la vitesse maximum et l'extension des avalanches de neige lourde, données par Voellmy (1955) sont considérees comme des cas particuliers d'un modèle plus général proposé par Perla et autres (1980). Des équations analogues à celles de Voellmy en sont déduites et ont défini leurs approximations du point de vue d'un modèle plus général.

ZuSAMmenfassung. Ableitung der Voellmy'schen Gleichungen für das Geschwindigkeitsmaximum und die Reichweite von Lawinen aus einem Massenschwerpunktsmodell. Die gewöhnlich benutzten Gleichungen für das Geschwindigkeitsmaximum und die Reichweite abgehender Lawinen, die von Voellmy (1955) hergeleitet wurden. werden unter einer von Perla et al. (1980) vorgeschlagenen, allgemeineren Modellvorstellung betrachtet. Analoge Gleichungen zu denen von Voellmy werden aufgestellt: der Grad der Näherung aus der Sicht des erweiterten Modells wird bestimmt.
\end{abstract}

\section{VOELLMY EQUATIONS FROM THE PCM MODEL}

The differential equation governing the speed $V$ of the centre-of-mass of a dry-flowing avalanche as given by the model of Perla and others (1980), and here called the PCM Model, is

$$
\frac{\mathrm{d} V}{\mathrm{~d} t}=\frac{1}{2} \frac{\mathrm{d} V^{2}}{\mathrm{~d} S}=g[\sin \theta(S)-\bar{\mu} \cos \theta(S)]-\frac{\bar{D}}{M} V^{2}
$$

where $\theta(S)$ is the slope angle at position $S$ along the incline, $g$ is acceleration due to gravity, $\bar{\mu}$ is a constant coefficient of sliding friction, and $\bar{D} / M$ is a constant turbulent drag coefficient written as a ratio of drag $D$ to mass $M$, and $t$ is time.

In order to derive equations similar to those of Voellmy (1955), Equation (1) is re-stated in a simple way. The centre-of-mass concept is retained but the bulk of flowing snow is distributed over a flow height $H$ and an area of extent $A$ over which the avalanche is in contact with the snow or earth surface. Equation (1) re-stated, becomes

$$
\frac{\mathrm{d} V^{2}}{\mathrm{~d} S}=2 g[\sin \theta(S)-\bar{\mu} \cos \theta(S)]-\frac{2 g}{\xi H} V^{2}
$$

where the turbulent drag term is assumed to be $\frac{1}{2} \rho A C_{\mathrm{D}} V^{2}$ and $\bar{\rho}$ is the average density of the flowing part of the avalanche, called the core. This drag term is written in the form of an inverse drag coefficient. following Voellmy, with the conversion $g / \xi H=\bar{D} / M=C_{\mathrm{D}} / 2 H$.

It is of interest that $H$, the average core flow height, is generally only a fraction of the powder or dust cloud height for dry avalanches. Measurements with load cells through the cross-section of dry-flowing avalanches at the Tupper I avalanche path, Rogers Pass, British Columbia, show that $H$ is on the order of 1 to $2 \mathrm{~m}$ for that particular path and may be much less than the powder-cloud height, which is characterized by suspended material.

In order to derive Voellmy's equations from Equation (2), consider the simple geometry he assumed. 
Figure I depicts this in terms of two segments of constant angle: (i) the upper segment of length $S_{0}$ and slope angle $\theta_{0}$, defining the region where the avalanche accelerates; and (ii) a lower segment of length $S_{\mathrm{r}}$ and slope angle $\theta_{\mathrm{r}}$ representing the run-out or deceleration region of the avalanche. In order to use Voellmy's method the path must be broken into two such segments by assuming the point at which deceleration begins.

The solution of Equation (2) with $\theta(S)=\theta_{0}$ is given by

$$
V(S)=\left|C_{0} \exp (-2 g S / \xi H)+\xi H\left(\sin \theta_{0}-\bar{\mu} \cos \theta_{0}\right)\right|^{1 / 2}
$$

where $C_{0}$ is a constant determined by initial conditions. With $V(0)=0, C_{0}=-\xi H\left(\sin \theta_{0}-\mu \operatorname{\mu } \cos \theta_{0}\right)$, and Equation (3) becomes

$$
V(S)=\left|\xi H\left(\sin \theta_{0}-\bar{\mu} \cos \theta_{0}\right)(1-\exp (-2 g S / \xi H))\right|^{1 / 2} .
$$

Now with the assumption $\left(2 g S_{0} / \xi H\right) \gg 1$, at the end of the first segment Equation (4) becomes

$$
V_{0}=V\left(S_{0}\right)=\left|\xi H\left(\sin \theta_{0}-\bar{\mu} \cos \theta_{0}\right)\right|^{1 / 2} .
$$

This equation is commonly used to calculate maximum speed for flowing avalanches by the Voellmy method.

With $\theta=\theta_{\mathrm{r}}$, the solution for the second or run-out segment becomes

$$
V(S)=\left|C_{\mathrm{r}} \exp (-2 g S / \xi H)-\xi H\left(\bar{\mu} \cos \theta_{\mathrm{r}}-\sin \theta_{\mathrm{r}}\right)\right|^{1 / 2} .
$$

Using the initial condition $V(0)=V_{0}$, when $S=0$, Equation (6) yields

$$
\left.V(S)=\left\{\mid V_{0}^{2}+\xi H\left(\bar{\mu} \cos \theta_{\mathrm{r}}-\sin \theta_{\mathrm{r}}\right)\right] \exp (-2 g S / \xi H)-\xi H\left(\bar{\mu} \cos \theta_{\mathrm{r}}-\sin \theta_{\mathrm{r}}\right)\right\}^{1 / 2} .
$$

In addition, $\bar{\mu}$ is greater than zero, as required for flowing avalanches, and the condition $\mathrm{d} V / \mathrm{d} S \leqslant 0$ must be applied at the beginning of the run-out zone so that the avalanche decelerates on the lower slope. Application of these conditions to Equation (7) implies that $\bar{\mu}$ is in the range $\tan \theta_{\mathrm{r}} \leqslant \bar{\mu} \leqslant \tan \frac{1}{2}\left(\theta_{0}+\theta_{\mathrm{r}}\right)$.

Application of the condition $V\left(S_{\mathrm{r}}\right)=0$ to Equation (7) defines the stop position of the centre-of mass. and the exponential is written as $\exp \left(-2 g S_{\mathrm{r}} / \xi H\right) \approx 1-2 g S_{\mathrm{r}} / \xi H$. The latter condition amounts to the assumption that $\frac{1}{2}\left(2 g S_{\mathrm{r}} / \xi H\right)^{2} \ll 1$.

With these assumptions the solution for the run-out distance or the length of the deceleration region of the avalanche becomes

$$
S_{\mathrm{r}}=\frac{V_{0}^{2}}{2 g\left(\bar{\mu} \cos \theta_{\mathrm{r}}-\sin \theta_{\mathrm{r}}+V_{0}^{2} / \xi H\right)} .
$$

Equation (8) may be compared to the approximate run-out equation given by Voellmy (1955) with the modification suggested by Salm (1979)

$$
S_{\mathrm{r}}=\frac{V_{0}^{2}}{2 g\left(\bar{\mu} \cos \theta_{\mathrm{r}}-\sin \theta_{\mathrm{r}}+V_{0}^{2} / 2 \xi H\right)} .
$$

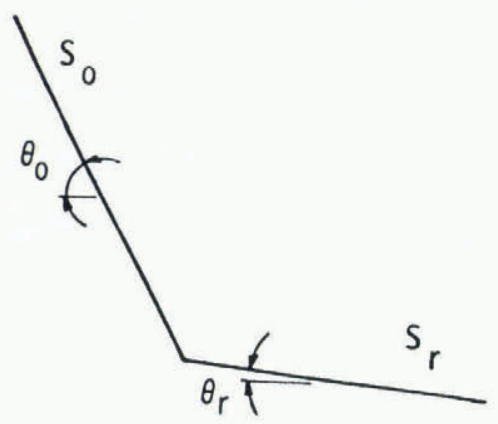

Fig. 1. Geometry for two-segment approximation of avalanche path used by Voellmy (1955). The two segments have lengths $S_{0}$ and $S_{\mathrm{r}}$ and slope angles $\theta_{0}$ and $\theta_{\mathrm{r}}$. 
Salm's modification as expressed by Equation (9) amounts to the replacement of $\tan \theta_{\mathrm{r}}$ by $\sin \theta_{\mathrm{r}}$ in the denominator and the use of $H$ instead of $H_{\mathrm{D}}$, which is defined in the original equations given by Voellmy as the average height of debris piled up. Inspection of Equations (8) and (9) shows that they are identical except for a factor of two in the third term of the denominator. Using the original Voellmy equations and ignoring the replacement $\sin \theta_{\mathrm{r}} \rightarrow \tan \theta_{\mathrm{r}}$, it is necessary to assume that $H_{\mathrm{D}}=0.5 H$ to get equivalence between Equation (8) and the original equations. Field observations at Rogers Pass, British Columbia, show that there is no justification for assuming $H_{\mathrm{D}}=0.5 H$ if $H$ is taken as the flow height of the core material.

The two assumptions needed to obtain Equations (5) and (8), $\left(2 g S_{0} / \xi H\right) \geqslant 1$, with $\frac{1}{2}\left(2 g S_{\mathrm{r}} / \xi H\right)^{2} \ll 1$, imply that the deceleration region $S_{\mathrm{r}}$ is much shorter than the acceleration region $S_{0}$. Velocity profile data by Bryukhanov (1968) and Van Wijk (1967) show that this is not generally a safe assumption.

It is of further interest that for the two-segment problem there is no need to make the restrictive assumptions $\left(2 g S_{0} / \xi H\right) \gg 1$ and $\frac{1}{2}\left(2 g S_{\mathrm{r}} / \xi H\right)^{2} \ll 1$ which were necessary to obtain equations analogous to Voellmy's. Equation (4) may be used to give the maximum speed, $V\left(S_{0}\right)=V_{0}$; whereas the condition $V\left(S_{\mathrm{r}}\right)=0$ applied to Equation (7) gives

$$
S_{\mathrm{r}}=\frac{\xi H}{2 g} \ln \left[\frac{V_{0}^{2}+\xi H\left(\bar{\mu} \cos \theta_{\mathrm{r}}-\sin \theta_{\mathrm{r}}\right)}{\xi H\left(\bar{\mu} \cos \theta_{\mathrm{r}}-\sin \theta_{\mathrm{r}}\right)}\right]
$$

as the version of Equation (8) without the restrictive approximations. This equation is identical to one derived by Salm (1979) except that he has given $H$ a slightly different interpretation.

\section{Discussion}

Equations analogous to those of Voellmy have been derived for maximum speed and avalanche runout from the PCM Model. Attention has been focused on the approximations necessary for development of such similar equations and it is emphasized that these are not, in general, good assumptions based on field experience and measurements. Voellmy's actual derivation began from essentially the same differential equation and the two-segment geometry assumed here. Voellmy`s derivation, however. is based on energy considerations and the approximations used have been, to the present. unclear in terms of the PCM Model. The purpose of this short note is to clarify the relation between Voellmy's equations and the PCM Model.

\section{ACKNOWLEDGEMENT}

This paper is a contribution from the Division of Building Research, National Research Council of Canada, and is published with the approval of the Director of the Division.

MS. received 7 June 1982 and in revised form 11 October 1982

\section{REFERENCES}

Bryukhanov, A. V. 1968. Stéréo photogrammetrie terrestre à cadence rapide des avalanches de neige. Socielé Français de Photogrammetrie. Bulletin No. 29, p. 9-28.

Perla, R. I., and others. 1980. A two-parameter model of snow-avalanche motion, by R. |I.| Perla. T. T. Cheng, and D. M. McClung. Journal of Glaciology, Vol. 26, No. 94, p. 197-207.

Salm, B. 1979. Fliessübergänge und Auslaufstrecken von Lawinen. Interner Bericht des Eidg. Institutes für Schmeeund Lawinenforschung, Nr. 566.

Van Wijk, M. C. 1967. Photogrammetry applied to avalanche studies. Journal of Glaciology: Vol. 6. No. 48. p. $917-33$.

Voellmy, A. 1955. Über die Zerstörungskraft von Lawinen. Schweizerische Bauzeitung, Jahrg. 73. Ht. 12, p. 159-62: Ht. 15, p. 212-17; Ht. 17, p. 246-49; Ht. 19, p. 280-85. 